\title{
Thermal properties of group components of the pitch-PET compositions
}

\author{
Grzegorz Makomaski ${ }^{1} \cdot$ Janusz Zieliński $^{1}$
}

Received: 13 December 2016/Accepted: 14 March 2017/Published online: 24 March 2017

(C) The Author(s) 2017. This article is an open access publication

\begin{abstract}
The study results of thermal properties of group components insoluble in quinoline and toluene of pitchpolymer compositions by differential scanning calorimetry, physicochemical and thermal properties, and structure of pitch-polymer compositions were presented. For pitchpolymer compositions containing 10-50 mass\% waste polymer, softening point, coking value, content of components insoluble in toluene and quinoline, thermal analysis, and colloidal structure by fluorescence microscope were carried out.
\end{abstract}

Keywords Group components · DSC · Pitch-polymer compositions $\cdot$ Coal tar pitch $\cdot$ Poly(ethylene terephthalate)

\section{Introduction}

Coal tar pitch (CTP) is an important feedstock of carbochemical origin of the processing of coal tar fordem as an inevitable by-product of the coking of coal. Coal tar pitch is used for the production of, i.e., carbon anodes, graphite electrodes, fireproof materials, carbon-carbon composites, carbon fibers, carbon adsorbents [1,2]. Bitumens originating from coal, similarly as petroleum asphalts, can be treated as colloidal-dispersive systems. Micelles composed of $\alpha_{2}$ components and partly of $\alpha_{1}$ components form dispersed phase, while oils ( $\gamma$ components) and partly $\beta$ components are the dispersing phase [3].

In Warsaw University of Technology, Institute of Chemistry in Plock, studies have been carried for several

Grzegorz Makomaski

Grzegorz.Makomaski@pw.edu.pl

1 Faculty of Civil Engineering, Mechanics and Petrochemistry, Warsaw University of Technology, Lukasiewicza 17, 09-400 Plock, Poland years on the preparation of coal-originated bituminous materials modified with polymers. Recently taken studies on the use of pitch-polymer compositions for the production of porous materials [4-6]. Modification of coal tar pitch with polymers influences also significantly its group components and properties. Chemical structure is a factor directly determining properties of each of the components of bitumen-polymer compositions and simultaneously has an impact on the possibility to from a specific structure of a given composition, on which in turn its properties depend [7-11]. Pitch-polymer compositions can be treated as microheterogeneous systems, colloidal, biphase, generally exhibiting uniform dispersion of particles composed of polymer macromolecules and probably of $\alpha$ components of coal tar pitch [12]. In this work, the study results of thermal properties of group components insoluble in quinoline (QI) and toluene (TI) of pitch-polymer compositions by differential scanning calorimetry, thermal and physicochemical properties, and structure of pitch-polymer compositions were presented. Conducted studies are complementary to other methods of evaluation the homogeneity and level of dispersion of polymer in bitumen-polymer compositions. Furthermore, these are preliminary studies to evaluate the effect of phenomena occurring during processes of modification of coal-originated bitumens with macromolecular compounds on the porous structure derived activated carbons.

\section{Experimental}

The raw materials used in this study were CTP from Institute for Chemical Processing of Coal in Zabrze and waste poly(ethylene terephthalate) (PET). Pitch-polymer compositions containing from 10 to 50 mass $\%$ waste PET 
were prepared in the conditions allowing to obtain homogeneous and stable mixtures. The components were homogenized in the temperature $260{ }^{\circ} \mathrm{C}$, during $0.5 \mathrm{~h}$. The composition of mixtures is presented in Table 1.

For the group components of coal tar pitch and pitchpolymer compositions were carried out the thermal properties by the means of scanning differential calorimeter Netzsch Maia F3. The measurements were noted in the range of temperatures from 25 to $520^{\circ} \mathrm{C}$, with the temperature increase rate of $10 \mathrm{~K} \mathrm{~min}^{-1}$. For CTP and pitchpolymer compositions, the following measurements were noted:

- compositions' beginning temperature by thermogravimetric method. Thermogravimetric curves (TG and DTG) were recorded by means of Derivatograph-C (produced by MOM Budapest) on heating up to $1000{ }^{\circ} \mathrm{C}$ with a rate of $10 \mathrm{~K} \mathrm{~min}^{-1}$ in air atmosphere [13, 14],

- softening point by "Ring and Ball" method (SP) according to the PN-EN 1427:2009 standard,

- coking value (CV) according to the PN-C-97093:1993 standard,

- content of components insoluble in toluene (TI) according to the method elaborated in the Institute of Chemistry, Warsaw University of Technology in Plock,

- content of components insoluble in quinoline (QI) according to the PN-C-97058:1999 standard.

The colloidal structure of pitch-polymer compositions by Olympus BX41 microscope was analyzed. In the study of colloidal structure of pitch-polymer compositions, adopted technique of preparing of samples for study was press molding of compositions on the microscopic slide by a hydraulic press [12].

\section{Results and discussion}

In Figs. 1 and 2, DSC curves of group components of coal tar pitch and pitch-polymer compositions and DSC curve of PET are presented.

Basing on the course of DSC curves of TI components of pitch-poly(ethylene terephthalate) compositions
(Fig. 1), it was found that transitions characteristic for waste poly(ethylene terephthalate) occurred in them as an effect of temperature, including:

- endothermic transition, occurring for group components in the range of temperatures from 230.6 to $245.5^{\circ} \mathrm{C}$ (enthalpy values from 9.35 to $38.79 \mathrm{~J} \mathrm{~g}^{-1}$ ), related to PET melting [15],

- endothermic transition, related probably to decomposition of samples. The onset of this transition for studied compositions occurred in the temperatures from 382.7 to $398.3{ }^{\circ} \mathrm{C}$.

Basing on the course of DSC curves of QI components of pitch-poly(ethylene terephthalate) compositions (Fig. 2), it was found that transitions characteristic for waste poly(ethylene terephthalate) occurred in them as an effect of temperature, including:

- endothermic transition, occurring for group components in the range of temperatures from 233.9 to $250.5{ }^{\circ} \mathrm{C}$ (enthalpy values from 27.58 to $53.33 \mathrm{~J} \mathrm{~g}^{-1}$ ), related to PET melting,

- endothermic transition, related probably to decomposition of samples. The onset of this transition for studied compositions occurred in the temperatures from 380.5 to $400.8{ }^{\circ} \mathrm{C}$.

The analysis of DSC curves of TI and QI components of the pitch-PET compositions found that, in the group components of the compositions dominant physical interactions between of group components of CTP and polymer macromolecules. On DSC curves of components insoluble in toluene and quinoline it was found transitions characteristic of poly(ethylene terephthalate).

In Fig. 3 TG curves and in Fig. 4 DTG curves of coal tar pitch and pitch-polymer compositions are presented. The results of measurements of thermal and physicochemical properties of CTP and pitch-poly(ethylene terephthalate) compositions are presented in Table 1.

Basing on the course of TG and DTG curves of coal tar pitch, it was found that thermal decompositions of CTP proceeded in one steps. The beginning of this process occurred at $285.2{ }^{\circ} \mathrm{C}$. Thermal decompositions of pitchpolymer compositions proceeded in two steps. The

Table 1 Thermal and physicochemical properties of CTP and pitch-polymer compositions

\begin{tabular}{llllrr}
\hline Compositions $/$ mass $\%$ & Decomposition beginning temperature $/{ }^{\circ} \mathrm{C}$ & $\mathrm{SP} /{ }^{\circ} \mathrm{C}$ & $\mathrm{CV} / \mathrm{mass} \%$ & $\mathrm{TI} / \mathrm{mass} \%$ & $\mathrm{QI} / \mathrm{mass} \%$ \\
\hline $\mathrm{CTP}$ & 285.2 & 107.0 & 53.03 & 34.21 & 7.14 \\
$90 \mathrm{CTP}+10 \mathrm{PET}$ & 287.3 & 127.0 & 53.62 & 45.80 & 13.31 \\
$75 \mathrm{CTP}+25 \mathrm{PET}$ & 364.8 & 166.0 & 50.10 & 43.10 & 29.43 \\
$65 \mathrm{CTP}+35 \mathrm{PET}$ & 348.8 & 225.5 & 47.71 & 53.03 & 37.69 \\
$50 \mathrm{CTP}+50$ PET & 331.9 & 236.0 & 38.00 & 68.50 \\
\hline
\end{tabular}




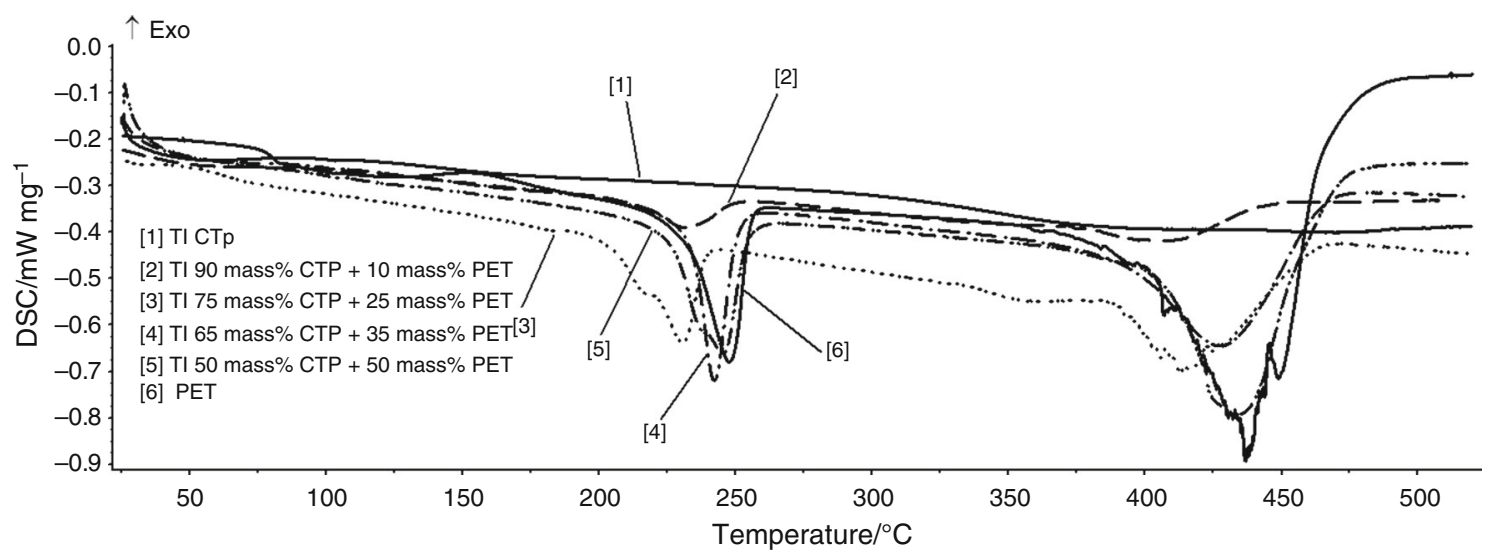

Fig. 1 DSC curves of TI components of coal tar pitch, pitch-PET compositions and PET

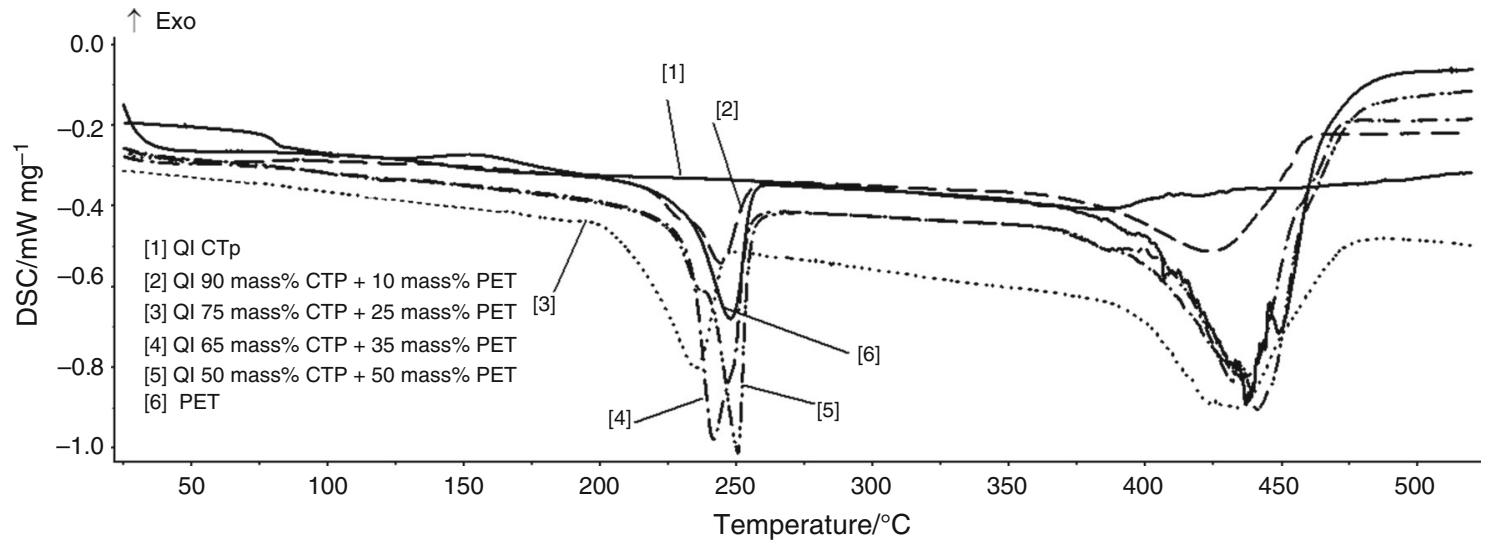

Fig. 2 DSC curves of QI components of coal tar pitch, pitch-PET compositions and PET

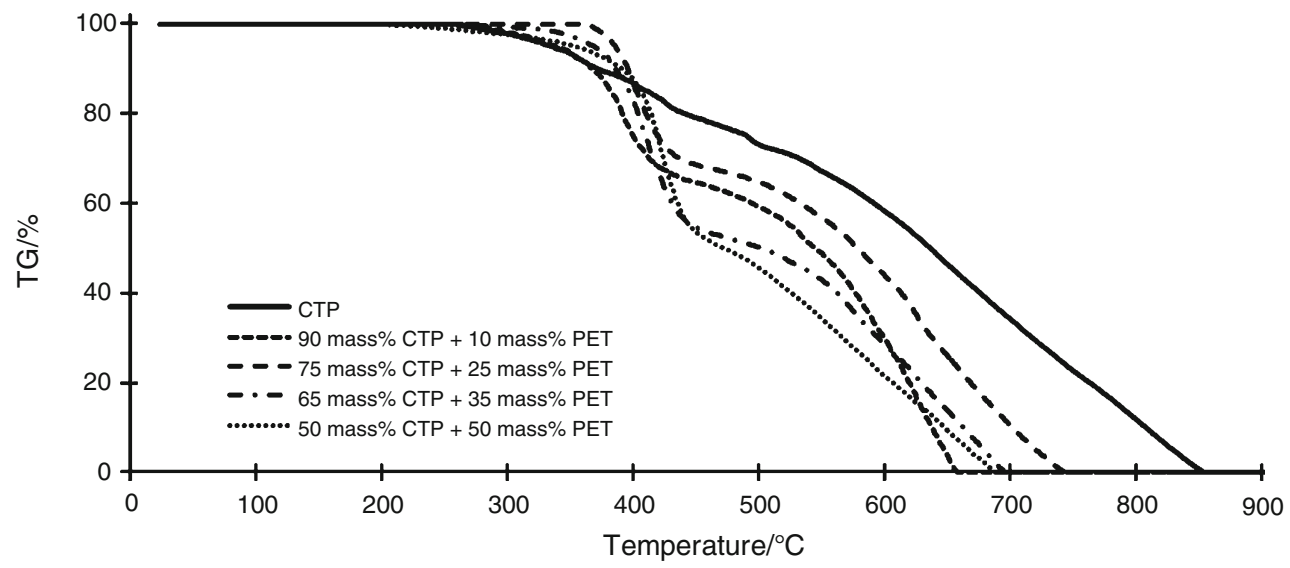

Fig. 3 TG curves of coal tar pitch and pitch-PET compositions

beginning of this process for studied compositions occurred in the temperature from 287.3 to $364.8^{\circ} \mathrm{C}$. Both the intensity and temperature range of decomposition process depended on the amount of waste polymer:

- compositions containing $\leq 25$ mass $\%$ of waste PET lost $32-36 \%$ of their mass in the first stage at $287.3-460{ }^{\circ} \mathrm{C}$,
- compositions containing $\geq 35$ mass $\%$ of waste PET lost $48-51 \%$ of their mass in the first stage at $331.9-480{ }^{\circ} \mathrm{C}$.

In the process of thermal decomposition of coal tar pitches, several component processes follow in parallel. Pyrolysis and the accompanying evolution of volatile fractions can be associated with destruction of 


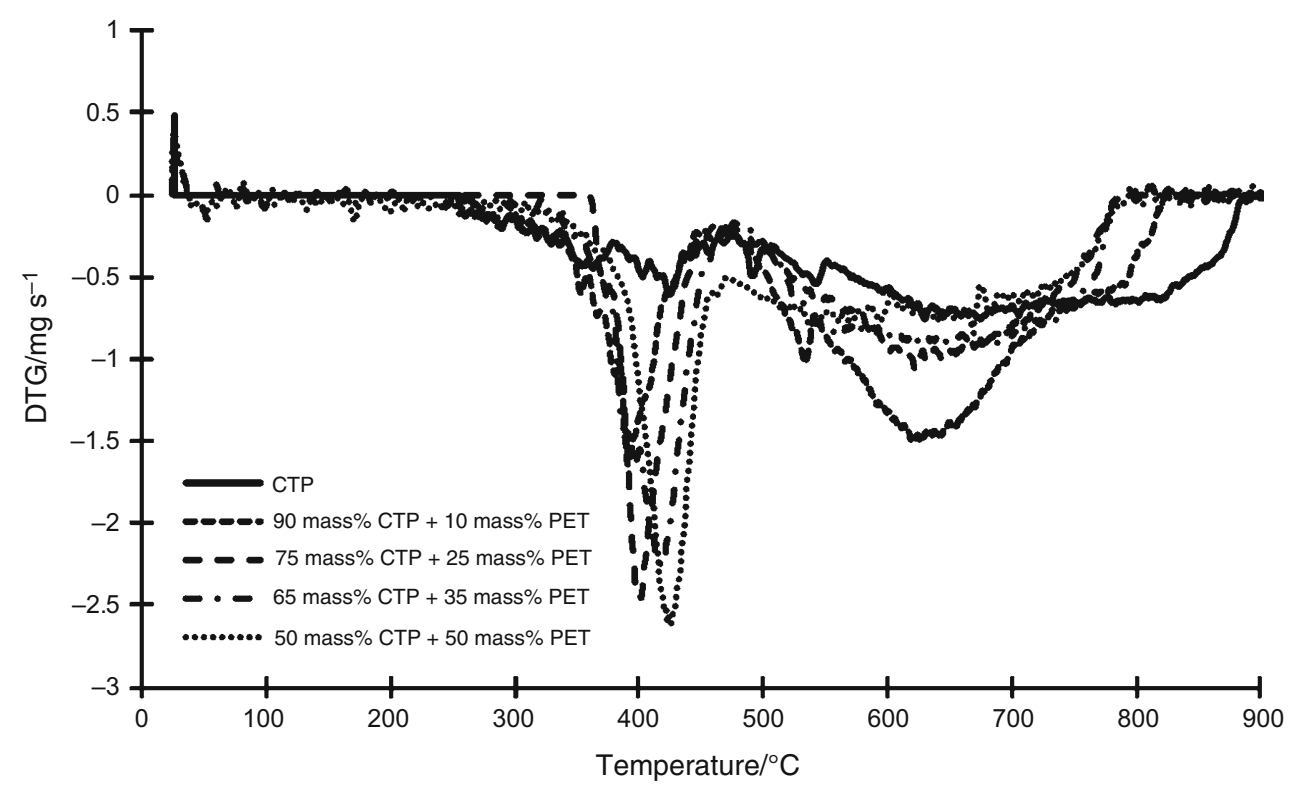

Fig. 4 DTG curves of coal tar pitch and pitch-PET compositions

(a)

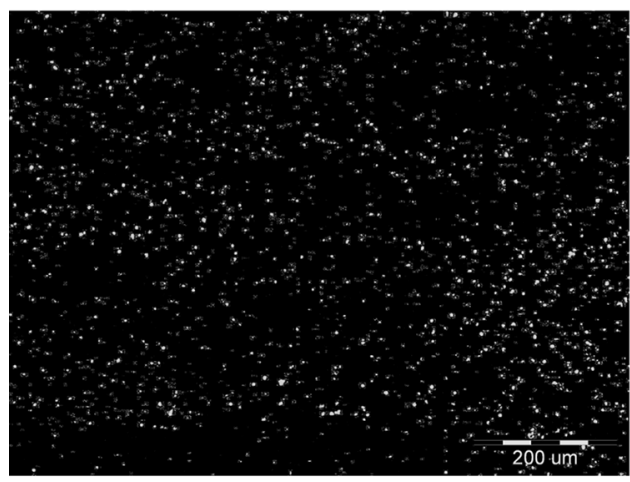

(c)

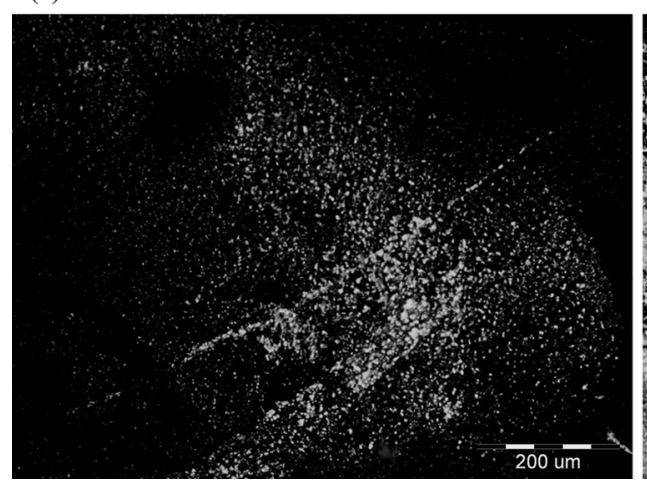

(b)

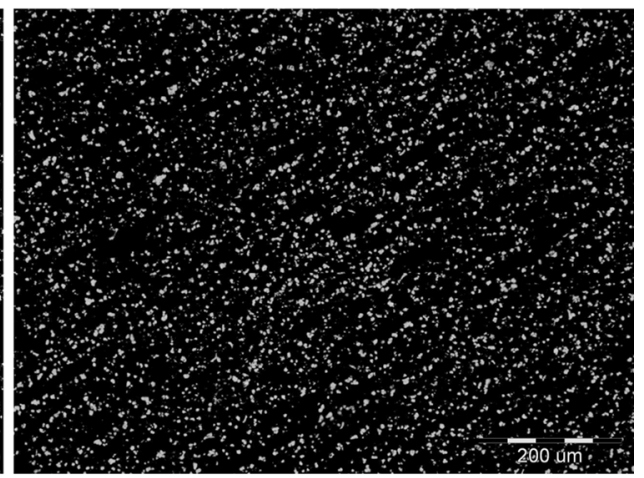

(d)

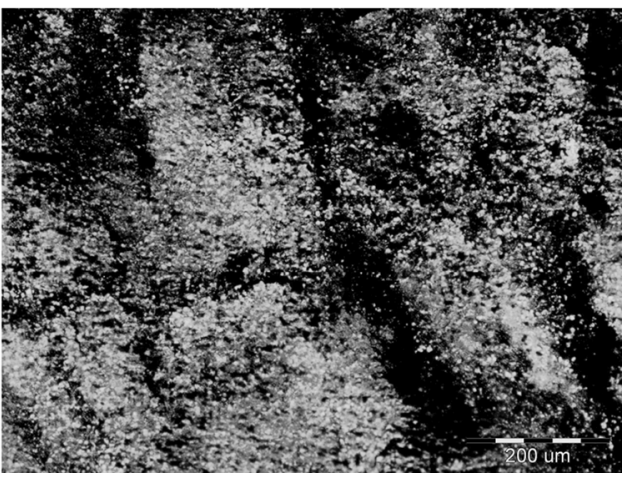

Fig. 5 Microscopic images of the structure of pitch-PET compositions containing: a 10 mass\% of waste PET, b 25 mass $\%$ of waste PET, c 35 mass \% of waste PET, d 50 mass\% of waste PET 
hydrocarbons, partial abstraction of functional groups, formation of simple compounds $\mathrm{CO}_{2}$ and $\mathrm{CH}_{4}$, condensation and polymerization of resulting particles [16-18]. In the process of thermal decomposition of pitch-polymer compositions, reactions may occur between decompositions products of CTP and PET. Addition of waste PET into CTP influenced on the deepening process of thermal decompositions of coal-originated bitumen.

Addition of waste poly(ethylene terephthalate) caused changes occurring in studied compositions as an effect of temperature, while the biggest changes were observed in decomposition beginning temperature. The increase of poly(ethylene terephthalate) addition into coal tar pitch caused the increase of decomposition beginning temperature up to $364.8^{\circ} \mathrm{C}$. The addition of waste poly(ethylene terephthalate) significantly influenced the softening point of coal tar pitch. With the increase in PET in the compositions the softening point increased. For the composition containing 50 mass\% of PET, the softening point compared to the unmodified pitch increased by $129^{\circ} \mathrm{C}$.

With the increase in waste PET in the compositions, the cooking value decreased and so the yield of residue after high-temperature carbonization process. In particular, significant changes occurred for compositions containing 50 mass\% of the waste, where coking value was lower by 15 mass\% compared to coal tar pitch.

The changes of thermal properties of pitch-PET compositions were probably caused by the change of group components of the CTP. Addition of waste poly(ethylene terephthalate) into coal tar pitch increased the amount of components insoluble in quinoline and toluene.

In Fig. 5, microscopic images of pitch-PET compositions obtained using fluorescence microscope are presented. On obtained microscopic images, similarly as in the case of petroleum bitumens, carbon bitumen phase is observed in black color.

Structures of compositions containing $\leq 25$ mass\% PET had uniform level of dispersion and dispersed polymer particles had round and regular shapes. The increase in waste PET amount in compositions caused the increase of the amount and size of dispersed particles. For the composition containing $\geq 35$ mass $\%$ of waste poly(ethylene terephthalate), agglomerates of irregular shape could be observed, which were formed from aggregates containing polymer macromolecules and probably $\alpha_{1}$ and $\alpha_{2}$ components of coal tar pitch. Phase inversion of the dispersion was observed. It has to be presumed that with the increase in waste PET amount in compositions the development of micellar areas occurred due to strong physical interactions between the components, which is indicated by high content of components insoluble in toluene and quinoline in compositions.

\section{Conclusions}

The use of differential scanning calorimetry in the studies on group components of pitch-polymer compositions made possible the determination of their phase transitions temperatures, and evaluation of effects between group components of CTP and polymer macromolecules. The analysis of DSC curves of group components of the pitch-polymer compositions found that, in the group components of the compositions, the dominant role was played by the macromolecules of PET. On DSC curves of components insoluble in toluene and quinoline, it was found transitions characteristic of poly(ethylene terephthalate).

Modification of coal tar pitch with waste polymer significantly influences the physicochemical properties and group components of the bitumen. Addition of waste PET into coal tar pitch caused increase in softening point and decomposition beginning temperature, the amount of components insoluble in toluene and quinoline, while coking value in pitch-PET compositions decreased.

Pitch-polymer compositions can be treated as microheterogeneous systems, colloidal, biphase, generally exhibiting uniform dispersion of particles composed of polymer macromolecules and probably of $\alpha_{1}$ and $\alpha_{2}$ components of coal tar pitch. Observed microscopic images allowed pointing out the following dependences between the properties of pitch-polymer compositions and their structure. The increase in the size of dispersed aggregates caused the increase of softening point and content of TI and QI components and reduction of coking value. It has to be surmised that the increase in the amount and size of dispersed aggregates can favor the creation of well-developed porous structures of activated carbons obtained from pitchpolymer compositions in the process of carbonization and next activation.

Open Access This article is distributed under the terms of the Creative Commons Attribution 4.0 International License (http://creative commons.org/licenses/by/4.0/), which permits unrestricted use, distribution, and reproduction in any medium, provided you give appropriate credit to the original author(s) and the source, provide a link to the Creative Commons license, and indicate if changes were made.

\section{References}

1. Collin G. Production and application of coal-tar pitch. In: Proceedings international conference on structure and properties of coals. Wroclaw; 1991. p. 154-6.

2. Zhong L, Zhang Y, Ji Y, Norris P, Pan W. Synthesis of activated carbon from coal pitch for mercury removal in coal-fired power plants. J Therm Anal Calorim. 2016;123:851-60.

3. Zieliński J. The studing of structure and properties of bitumempolymer compositions. Warsaw: Warsaw University of Technology; 1991. 
4. Makomaski G, Ciesińska W, Zieliński J. Thermal properties of pitch-polymer compositions and derived activated carbons. J Therm Anal Calorim. 2012;109:767-72.

5. Makomaski G, Zieliński J, Zdziarski M. Effect of some carbonization and activation parameters on the sorption properties of carbon adsorbents made by carbonization of pitch-polymer blends. Przem Chem. 2015;94:694-7.

6. Makomaski G. The preparation of porous materials form waste polymers-modified carbon bitumens. Przem Chem. 2016;95:1378-80.

7. Zieliński J, Osowiecka B, Liszyńska B, Ciesińska W, Polaczek J, Kubica K. Benzo[a]pyrene in coal tar pitch: chemical conversion in situ by alkylation. Fuel. 1996;75:1543-8.

8. Zieliński J, Pacewska B, Brzozowska T, Machnikowski J. Studies on thermal decomposition of pitch-polymer compositions. J Therm Anal Calorim. 2000;60:293-7.

9. Ciesińska W, Zieliński J, Brzozowska T. Thermal treatment of pitch-polymer blends. J Therm Anal Calorim. 2009;95:193-6.

10. Hlatshwayo SR, Focke WW, Ramjee S, Rand B, Mangala N. Rheological behavior and thermal properties of pitch/poly(vinyl chloride) blends. Carbon. 2013;51:64-71.

11. Grzyb B, Machnikowski J, Weber JV. Mechanism of co-pyrolysis of coal-tar pitch with polyvinylpyridine. J Anal Appl Pyrolysis. 2004;72:121-30.
12. Makomaski G. Study on the structure of pitch-polymer compositions by fluorescence microscope. Colloid Polym Sci. 2015;293:297-301.

13. Pacewska B, Szychowski D. Mineral-carbon sorbents based on aluminium hydroxide and atactic poly(propylene). J Therm Anal Calorim. 2001;65:481-9.

14. Pacewska B, Szychowski D, Kluk O. Adsorption and structural properties of mineral-carbon sorbents. J Therm Anal Calorim. 2002;67:773-87.

15. Przepiórski J, Karolczyk J, Tsumura T, Toyoda M, Inagaki M, Morawski A. Effect of some thermally unstable magnesium compounds on the field of char fordem from poly(ethylene terephthalate). J Therm Anal Calorim. 2012;107:1147-54.

16. Jeong H, Seo D, Park S, Hwang J. A comprehensive study on copyrolysis of bituminous coal and pine sawdust using TG. J Therm Anal Calorim. 2015;120:1867-75.

17. Coimbra R, Paniagua S, Escapa C, Calvo L, Otero M. Thermogravimetric analysis of the co-pyrolysis of a bituminous coal and pulp mill sludge. J Therm Anal Calorim. 2015;122:1385-94.

18. Rotaru A. Thermal analysis and kinetic study of petrosani bituminous coal from Romania in comparison with a sample of ural bituminous coal. J Therm Anal Calorim. 2012;110:1283-91. 